\title{
AS RELAÇÕES ENTRE BOATO E PODER NO MANUAL DO CANDIDATO ÀS ELEIÇÕES E NA RETÓRICA A HERÊNIO
}

\section{THE RELATIONS BETWEEN RUMOR AND POWER IN THE COMMENTARIOLUM PETITIONIS AND IN THE RHETORICA AD HERENNIUM}

Murilo Pereira Assumpção ${ }^{1}$

Resumo: Esse trabalho objetiva compreender as relações entre boato e poder na República romana tardia, tendo como base as fontes históricas Manual do candidato às eleições eRetórica a Herênio.

Palavras-chave: boato; Manual do candidato às eleições; Retórica a Herênio.

Abstract: This work aims to understand the relations between rumors and power in the late Roman Republic, based on the historical sources Commentariolum petitionis and Rhetorica ad Herennium.

Key words: rumor; Commentariolum petitionis; Rhetorica ad Herennium.

\section{Introdução}

O boato pode ser compreendido como um relato anônimo, informal, alternativo e não confirmado disseminado no espaço público e difundido de pessoa para pessoa a partir de relações cotidianas e de

\footnotetext{
${ }^{1}$ Graduando em História pela Universidade Estadual de Londrina, participante do projeto "Boato e poder na Roma antiga: Estudos comparados sobre a comunicação informal no último século da República e na Antiguidade Tardia" do Prof. Dr. Julio Cesar Magalhães de Oliveira e bolsista IC (UEL) no período de 01/11/2012 a 31/07/2013. Atualmente está sob a orientação da Prof. Dra. Monica Selvatici para a realização do Trabalho de Conclusão de Curso.
} 
laços entre elas. Compartilhados entre indivíduos, os boatos são difundidos em um contexto de interação social e quando se estabelece entre as partes um sentimento de "entre si".

No último século da República romana, período caracterizado pela crise, intensa disputa e participação política dentro de uma esfera pública de atuação, na qual as notícias circuladas eram importantes, os boatos também adquiriram relevância, pois eles impactavam a vida pública, social e política.

Após essa breve introdução sobre o boato, destacaremos a importância da opinião pública na Roma tardo republicana, dos usos políticos do boato e as relações entre boato e poder no contexto da República romana tardia, tendo como base duas fontes textuais provenientes deste período: o Manual do candidato às eleições, produzida por Quinto Cícero, e a Retórica a Herênio, atribuída a Cícero. Ao final, teceremos algumas considerações, o que não esgota as análises sobre o tema.

\section{A “opinião pública” na República romana tardia}

A República romana tardia é marcada por tensões, conflitos, enfrentamentos sociais e políticos internos e pelas reivindicações populares, o que se relaciona com a própria crise da República e com o início do Principado. Esse período também caracteriza-se pela importância da participação do povo na dinâmica sócio-política e pela mobilização do mesmo para a obtenção de seu apoio político.

Essa crise no último século da República romana tem 
antecedentes relacionados ao processo de expansão de Roma e de seu consequente Imperialismo. As riquezas decorrentes desse processo ocasionaram conflitos internos pelo controle e distribuição das mesmas, pois esses benefícios eram destinados, sobretudo, aos que detinham maior poder econômico e político, o que acentuava a diferenciação social dos mais ricos para com os mais pobres. Os pequenos camponeses deixaram suas terras, incorporadas pelos grandes proprietários, que também anexaram o ager publicus, em direção às cidades. A luta pela terra tornou-se intensa entre os ricos e os pobres, pois os primeiros opuseram-se à Reforma agrária e a outras reformas que prejudicassem a oligarquia senatorial, gerando o aumento das tensões pelo povo, que pressiona por mais direitos, e violentos conflitos sociais e políticos, que levaram a violentas guerras civis. Os embates entre populares e optimates assumem um caráter militar com o apoio de soldados e generais (GUARINELLO, 1987, p. 74-78).

As razões dessa crise têm sido há muito intensamente debatidas pela historiografia ${ }^{2}$. Para Mommsen, ocorre uma revolução romana decorrente das crises e do conflito entre a aristocracia e os populares. Já para autores do fim do século XIX e início do XX, como Matthias Gelzer, Münzer, Syme, Strasburger, Pauly-Wissowa, North, Roma seria dominada por uma oligarquia hereditária fechada, a qual detinha o poder social e político, sendo o povo, passivo em relação à nobilitas. Esse

\footnotetext{
${ }^{2}$ A seguir apresentamos brevemente algumas interpretações sobre a crise da República romana tardia e sobre o sistema político e social desse momento histórico, tendo como base DUPLÁ (2007), que tece uma análise ampla sobre esse assunto.
} 
modelo interpretativo é criticado desde os anos 1980 por Fergus Millar que enfatiza um elemento democrático em Roma, pois a importância do povo na vida política romana, nas eleições, seria inegável. Em contraposição a esta interpretação historiográfica, outros autores, tais como Martin Jehne, Hölkeskamp, ressaltam o consenso aristocrático, os rituais cívico políticos, a submissão da plebe. Eles insistem na importância central do Senado na política romana. Outra linha interpretativa caracterizada por Flaig, Beck, Hölkeskamp destaca a legitimação do sistema e do consenso através de meios de expressão simbólica e de rituais. Contudo, Duplá salienta que há uma ruptura do consenso social e político, além de conflitos e reivindicações populares nesse período histórico. Como podemos compreender, as interpretações recentes, tanto a de Millar como as de alguns de seus opositores, destacam a relevância do convencimento dos indivíduos e da opinião pública na sociedade romana tardo republicana. É nesse contexto que podemos entender a importância dos boatos.

A opinião pública pode ser definida como a expressão da participação do povo, do comportamento sócio-político e do juízo do mesmo em relação a algum assunto. Associa-se à troca de informações e à circulação de notícias dentro de um espaço público de relações sociais e políticas, no qual ocorre as discussões dos assuntos públicos pelos atores sociais e no qual as próprias opiniões públicas são formadas (FUNARI, 1998-1999, p. 115-124).

O âmbito da vida pública no último século da República romana associava-se às preocupações e reivindicações do povo, a sua 
participação, as suas opiniões e também às notícias que circulavam e, dentre elas, os boatos. Essas notícias informais impactavam as candidaturas, reputações, a fama dos envolvidos nos processos eleitorais para os quais os romanos atribuíam grande preocupação, pois eram muito disputadas, sendo o êxito eleitoral decorrente dos apoios e dos votos conseguidos através de uma boa imagem do candidato e de sua campanha eleitoral. As notícias circuladas anonimamente e informalmente também marcavam os julgamentos.

Os romanos utilizavam vários termos para designar os conceitos de boatos e fofocas. Cícero, por exemplo, em seu discurso a favor de Murena, utilizou os termos rumor e sermo para referir-se a expectatio muneris. $\mathrm{O}$ termo sermo foi empregado em fontes históricas principalmente como rumor e como sinônimo de conversação, o qual possui significado parecido com rumor, que se refere a conversas entre pessoas. Assim, autores latinos utilizavam expressões como sermo populi, sermo hominum, rumor populi (ROSILLO LÓPEZ, 2007, p. 114-115). Também utilizavam vários termos para definir o conceito de opinião pública, tais como: fama, existimatio, opinio, consensus hominum. No Manual do candidato às eleições, a fama forensis e a fama popularis eram importantes para as eleições, sendo influenciadas pelas fofocas e pelos rumores, os quais são referidos através do termo sermo pelo autor dessa fonte histórica (PINA POLO, 2010, p. 75).

Portanto, a República romana tardia, caracterizou-se pela intensa competição política, pela mobilização popular e por um espaço público no qual os cidadãos enfatizavam sua opinião e no qual as informações 
circulavam. É nesse contexto que os boatos adquiriram importância para a veiculação de informações e para a construção e desconstrução da fama e da reputação de um indivíduo, mantendo com o poder, com o âmbito da política e da sociedade romana, relações estreitas, influenciando-o de modo decisivo, o que destacaremos a seguir.

\section{Os usos políticos dos boatos na República romana tardia}

Os boatos não são elementos neutros, pelo contrário, influenciam de modo decisivo as tramas sociais, políticas, econômicas. Ao tornaremse verossímeis para os seus receptores, transformam-se em instrumentos confiáveis para a obtenção de uma informação, sendo importantes para a formação da opinião pública dos atores sociais e políticos, pois impactam de forma inegável o âmbito público e político da sociedade.

No período romano tardo republicano isso não era diferente. A força dos boatos nesse contexto político é indubitável, mantendo relações com o mesmo, o qual era alterado pelas notícias informais que circulavam, o que influenciava a luta pelo poder, determinava a construção e a desconstrução de reputações, das famas, do prestígio de determinado indivíduo. Esses elementos, os boatos, a fama, a reputação, estavam associados, o que era relevante na construção da opinião pública, pois esta influenciava a propagação favorável ou desfavorável de informações em relação a outrem, as eleições, a construção de imagens destas e dos candidatos a elas.

Os políticos romanos utilizavam os boatos como armas políticas nos momentos de grande competitividade como eram as eleições 
romanas tardo republicanas. Nesses momentos de decisão política, os boatos causavam apreensão nas lideranças políticas. A preocupação com os boatos e com a opinião pública influenciada por eles pelos políticos romanos no último século da República é exemplificada com Cícero, que, como homo novus, contava principalmente com sua fama, reputação e prestígio como orador para a construção de sua carreira política, já que não possuía nenhum ancestral prestigioso. Esse medo é destacado pelo próprio Arpinate: “'temo a los troyanos' temo a la opinión publica y a lo que dirán de mi, afirmo" (ROSILLO LÓPEZ, 2007, p. 133-134). Evidentemente, Cícero não poderia desconsiderar o poder dos boatos em uma sociedade caracterizada pelo movimento e pelo burburinho das ruas (FUNARI, 2004, p. 110).

A força dos boatos no contexto político e nas eleições refere-se às características destas na República romana tardia. A participação política nesse período era marcante, havendo um jogo movimentado e complexo pelo poder nas campanhas eleitorais, caracterizadas pela grande concorrência, pois os atores sociais e políticos participavam intensamente no espaço público, manifestando suas opiniões e discutindo, o que revelava suas preocupações e interesses.

Os candidatos ao pleito eleitoral objetivavam a fama, a glória e, evidentemente, a vitória, conseguida através de votos, de bons apoios, principalmente dos homens eminentes, influentes da sociedade, que contribuíam para a construção de uma imagem positiva do candidato e de sua campanha eleitoral, em detrimento dos maus apoios, que atraiam ódio, e, consequentemente, uma imagem negativa. Além dos apoios, as 
escolhas, as atividades, as relações, movimentavam a política e conferiam respeitabilidade à disputa eleitoral. Para atingirem seu objetivo, os candidatos utilizavam-se de grandes esforços, inclusive da difamação, da divulgação de notícias falsas, das críticas a certos concorrentes que se desejasse preterir junto ao povo, através de vários meios, dentre os quais, os boatos.

Embora a imagem negativa de certo indivíduo fosse enfatizada com frequência através de instrumentos políticos e eleitorais, tais como os boatos, a imagem positiva de determinado competidor também era: suas qualidades eram mencionadas, que, tornadas públicas, seriam fundamentais na disputa eleitoral e para a consequente vitória para o cargo almejado. Para isso, estratégias, técnicas e instrumentos eleitorais que objetivavam "fazer o candidato" eram utilizados. As virtudes e qualidades positivas, o prestígio do candidato, sua excelência e bondade, influenciariam o êxito nas campanhas eleitorais, o que também seria conseguido através de diferentes meios de persuasão e de cooptação nos diferentes espaços para o objetivo final: conquistar o eleitorado e vencer as eleições.

Isso era conseguido através de uma opinião favorável ao candidato, o que se relaciona a dinâmica e a transmissão dos boatos, que marcavam os comportamentos e os resultados eleitorais, pois tanto os positivos quanto os negativos poderiam ganhar crédito popular. Nessa perspectiva, o Manual do candidato às eleições evidencia ser uma importante fonte documental para o conhecimento de estratégias eleitorais de um candidato na República romana tardia. 
Assim como no contexto das eleições, os boatos exerciam força no contexto dos julgamentos, principalmente nos casos judiciais políticos, os quais deveriam ser mobilizados ou combatidos segundo o interesse do defensor ou do acusador no momento da argumentação dos mesmos, o que é evidenciado na Retórica a Herênio.

Com isso, no Manual do candidato às eleições e na Retórica a Herênio, percebemos relações importantes entre boato e poder, o que mencionaremos a seguir.

\section{Relações entre boato e poder no Manual do candidato às eleições ${ }^{3}$}

O Manual do candidato às eleições ${ }^{4}$ é uma carta destinada por Quinto Cícero a seu irmão Marco Túlio Cícero no contexto de sua candidatura ao consulado do ano 63 a. C. para que ele obtivesse êxito na eleição. Nela, Quinto Cícero concede conselhos e reflexões ao irmão sobre alguns assuntos, como a campanha eleitoral em questão, muito competitiva, a importância da mesma, o contexto sócio-político no qual estavam inseridos, os apoios e os adversários do Arpinate, desqualificando-os. Embora seja alvo de crítica textual e de discussões sobre sua autenticidade, através desse documento histórico obtemos importantes informações sobre: a política e as eleições do último século da Repúbli-

\footnotetext{
${ }^{3}$ Para esse trabalho utilizamos a tradução do Manual do candidato às eleições de Ricardo da Cunha Lima (2000).

${ }^{4}$ Para mais informações sobre o documento histórico Manual do candidato às eleições e sobre as eleições em Roma, ver "Novus sum, consulatum peto, Roma est: el commentariolum petitionis de Quinto Cicerón", de A. Duplá e "Breviário de uma Campanha Eleitoral: O Commentariolum Petitionis de Quinto Cícero", de A. C. P. G. Rocha da Silva (2010).
} 
ca romana, elementos estratégicos utilizados nas mesmas, a carreira de Marco Túlio Cícero, se considerarmos Quinto Cícero como o autor do Manual.

Nesse documento histórico são apresentadas relações entre boato e poder. Os boatos poderiam ser utilizados para a constituição de uma fama, de uma reputação positiva de um candidato e de uma imagem positiva de sua campanha às eleições. Segundo Quinto Cícero, seria necessário que determinadas características e atitudes positivas fossem enfatizadas, as quais gerariam opiniões favoráveis ao candidato, tornando-o, assim como sua candidatura, prestigiosos e populares.

Marco Túlio Cícero deveria utilizar sua eloquência, oratória e o prestígio, a fama e uma imagem adequada em sua vida privada e pública alcançados devido ao talento nessa atividade, além de relações sociais, políticas e econômicas decorrentes da mesma, para derrotar os adversários. O autor ressalta: "Portanto, já que você usou essa fama como trampolim e tudo o que você é deve a isso, trate de se apresentar muito bem preparado para os discursos" (Q.Cic.Pet.I.2).

A oratória seria essencial para debelar os boatos, para contraporse aos invejosos e para evitar os prejuízos, permitindo ao candidato expor suas ideias e projetos populares, suas qualidades, o que cria opiniões favoráveis a ele e, consequentemente, convence o eleitorado para que vote nele: "Assim, continue avançando cada vez mais por esse caminho que você tem trilhado e seja insuperável na oratória: isso mantém os homens em Roma e os alicia, e os impede de estorvá-lo ou prejudicá-1o" (Q.Cic.Pet.XIV.55). 
Outra atitude seria decisiva para a construção de uma boa reputação durante a campanha eleitoral: a busca de apoios, de amigos, os quais deveriam ser cabalados com ardor, e o estreitamento de relações sociais, políticas e econômicas em relação a eles. A busca de apoios entre os grupos determinantes e influentes para angariar mais votos e a constituição de amizades seriam necessárias para conferir uma boa imagem, prestígio e influência à campanha eleitoral: "você deve constituir amizades de todos os tipos: para ter uma boa imagem, homens com carreira e nome ilustres [...] conferem prestígio ao candidato" (Q.Cic.Pet.V.18). Essa busca de apoios também estaria relacionada a uma opinião pública favorável, à fama popular e à circulação de relatos, o que criaria uma imagem positiva do candidato e de sua campanha:

estou falando de procedimentos com os quais você pode dominar a massa, para ter a casa cheia antes mesmo do amanhecer, para arrebanhar muita gente com a esperança de sua proteção [...] para que espalhem aos ouvidos do maior número de eleitores um excelente relato a seu respeito (Q.Cic.Pet.XII.49).

Através dessas considerações percebemos que o candidato deveria forjar um perfil que se referisse a uma imagem positiva de si próprio e de sua candidatura para a vitória eleitoral. Quinto Cícero aconselha sobre isso: "cuide para que sua campanha inteira seja repleta de pompa, que seja brilhante, esplêndida e popular, que tenha uma imagem e um prestígio insuperáveis" (Q.Cic.Pet.XIII.52).

Isso seria conseguido também através das conversas que circulassem, de boatos favoráveis que construiriam uma boa fama do 
indivíduo. Além disso, determinadas atitudes e características pessoais seriam importantes, pois gerariam comentários positivos, opiniões populares, que modelariam uma boa reputação, a qual, por sua vez, também faria com que excelentes relatos do candidato fossem propagados.

Outra preocupação destacada pelo autor do Manual é a relacionada com as notícias, com os comentários que circulassem. Essas informações poderiam trazer consequências à imagem do candidato, modelando-a, e também a sua campanha, tornando-as positivas ou negativas, de acordo com o teor da notícia propagada.

Deste modo, traria benefícios à eleição do candidato a realização de cortejos numerosos, de passeatas com muitos seguidores, o que conferiria prestígio e poder e seria importante para o alargamento do círculo de amigos, de apoios e de relações, além de ser relevante para uma boa fama popular, para a reputação do candidato e, consequentemente, de sua campanha: "vá à praça central em horários definidos: é grande a reputação, é grande o prestígio conferido por um cortejo numeroso que se encaminha diariamente ao centro" (Q.Cic.Pet.IX.36). A visualidade e a audibilidade do candidato no espaço público eram essenciais para a fama popular e para a vitória eleitoral. O candidato deveria ser visto, observado, destacado, dizendo o que o eleitorado queria ouvir, relatando suas qualidades admiráveis e suas boas ações, o que acarretaria popularidade e opiniões públicas favoráveis a ele.

É no centro da cidade que os comentários, ideias e notícias 
circulariam e é nele que ecoaria uma imagem positiva do candidato e de sua campanha, pois através das passeatas e dos cortejos, os mais jovens trariam notícias e neles excelentes relatos sobre o candidato deveriam ser espalhados.

Além da preocupação com as pessoas e com as notícias que circulariam no centro da cidade, o autor ressalta a importância do "ouvir dizer": "Agora, você deve tomar o maior cuidado com o seguinte: se alguém lhe prometeu fidelidade e você ouvir ou descobrir que ele, como se diz, tem duas caras, finja que não ouviu ou percebeu isso" (Q.Cic.Pet.IX.35).

Outro ambiente no qual circulariam as notícias seria o caseiro, pois nele os escravos e os libertos faziam comentários que transformariam a reputação de um homem público. Em relação a isso, Quinto Cícero declara:

você deve trabalhar infatigavelmente para que cada pessoa que lhe é mais íntima (e sobretudo quem é de sua casa) o adore e deseje ardentemente que você tenha o maior sucesso possível [...] pois quase todo comentário que modela a reputação de um homem público provém de fontes caseiras (Q.Cic.Pet.V.17).

Assim sendo, a circulação de comentários e de notícias influenciariam a reputação de um candidato e a campanha às eleições do mesmo. Devido a este fato, o candidato deveria manter uma opinião honorável ao seu respeito para que sua corrida eleitoral tivesse uma imagem positiva e para que excelentes comentários fossem espalhados por seus apoiadores. 
Contudo, alguns boatos poderiam trazer ao candidato e a sua campanha consequências ruins, modelando a sua reputação e a imagem de seu pleito eleitoral de modo negativo. O candidato deveria estar atento e preocupado, procurando debelar os boatos que lhe fossem contrários.

O autor menciona que Marco Túlio Cícero deveria ser esforçado e cuidadoso, pois muitos lhe eram contrários:

Portanto, ao se candidatar ao mais alto cargo político e se dar conta dos interesses e sentimentos que lhe são fortemente contrários, é necessário dispor de todo raciocínio, cuidado, esforço e aplicação (Q.Cic.Pet.IV.15).

Além disso, se os bons apoios, prestigiosos e influentes, deveriam ser cabalados com ardor, os indivíduos que atraíam ódio por seu desprestígio, má fama e má reputação deveriam ser evitados, pois deles nada se poderia esperar de benefício, somente sua presença perniciosa que traria consequências negativas para a reputação e para a corrida eleitoral do candidato. $\mathrm{O}$ autor salienta:

Há outros, porém, que ou não têm condições de nada ou até atraem o ódio [...] e não possuem uma grande alma ou talento de que possam lançar mão num momento como este; quanto a esses, fique de olho bem aberto para identificá-los, a fim de não depositar esperança em alguém de pouca valia (Q.Cic.Pet.VII.24).

Na obra é mencionado, o que também influenciaria as reputações e as candidaturas, a atenção que o candidato deveria conceder ao 
fingimento, aos caluniadores, à bajulação, às armadilhas e às fofocas, pois Roma teria se convertido em um espaço de intrigas, calúnias, bajulação, armadilhas, mentiras, fofocas, inveja, ressentimento, vícios, pouca moralidade. Para se defender contra isso, a oratória deveria ser utilizada. Isso é evidenciado no seguinte trecho, no qual é ressaltado que em Roma

proliferam muitas armadilhas, muita mentira, muitos vícios de todo gênero e na qual devemos aguentar a arrogância de muitos, o atrevimento de muitos, a hostilidade de muitos, o desdém de muitos, o ódio e o estorvo de muitos [...] e seja insuperável na oratória; isso mantém os homens em Roma e os alicia, e os impede de estorvá-lo ou prejudicá-lo (Q.Cic.Pet.XIV.54-55).

A forma pela qual o autor apresenta esses conselhos nos permite inferir que o candidato deveria preocupar-se com o que poderia gerar comentários contrários a ele e a sua campanha às eleições e, nesse caso, os boatos desfavoráveis que lhe trouxessem prejuízos deveriam ser debelados através da oratória.

Alguns boatos também deveriam ser utilizados para prejudicar a candidatura de um adversário, sendo necessário que fossem promovidos para que gerassem comentários negativos que prejudicassem a fama e a campanha contra indivíduos que se desejasse preterir no pleito eleitoral.

Quinto Cícero salienta a má fama e as características negativas dos adversários de Marco Túlio Cícero, os quais, apesar da origem ilustre, seriam famosos pelos vícios. Em contraposição, o autor ressalta uma imagem positiva, as qualidades morais de seu irmão, que 
sobressairiam sobre os vícios e crimes de seus opositores. Isso evidencia que uma má fama e uma má reputação dos adversários poderiam ser utilizadas para o benefício de um candidato.

Como exemplo dessa imagem negativa dos adversários de Marco Túlio Cícero, citamos o seguinte trecho da carta:

E também é de grande ajuda à sua condição de homem novo o fato de que você está concorrendo com aristocratas de um caráter tal que não haverá ninguém que ouse dizer que conta mais a origem a favor deles que sua excelência moral a seu favor [...] Um homem ativo, laborioso, irrepreensível, eloquente, querido pelos magistrados, deve mesmo desejar tais concorrentes, ambos desde a juventude assassinos, ambos libertinos, ambos depauperados (Q.Cic.Pet.II.7-8).

Os boatos, a má fama e os comentários negativos que circulassem seriam, portanto, instrumentos a serem utilizados contra os adversários que se pretendesse prejudicar durante o período eleitoral, pois esses elementos modelariam negativamente a reputação e a candidatura de um concorrente às eleições.

\section{Relações entre boato e poder na Retórica a Herênio ${ }^{5}$}

A Retórica a Herênio é alvo de discussões sobre sua autenticidade e sua autoria é atribuída a Cícero, pois o texto circulou em códices que englobavam obras do autor e devido as supostas semelhanças com suas obras, mas há importantes diferenças com o pensamento e com o

\footnotetext{
${ }^{5}$ Para esse trabalho utilizamos a tradução da Retórica a Herênio de Ana Paula Celestino Faria e Adriana Seabra (2005).
} 
estilo dele. Sua composição, em forma de epístola, deu-se provavelmente entre os anos de 85 a. C. e 82 a. C. Há também discussões sobre o destinatário do tratado: Caio Herênio. O título original da fonte textual e o autor da mesma são desconhecidos.

Nessa fonte textual o autor escreve sobre o ofício do orador e a produção dos discursos retóricos. A Retórica refere-se ao saber, aos preceitos e regras da arte discursiva, que era importante para a vida pública na Roma tardo republicana, pois a argumentação, a persuasão dos cidadãos por meio da linguagem era a base de atividades públicas, como as eleições, os julgamentos. Os romanos atribuíam grande valor a arte da oratória, já que a vida pública associava-se à eloquência, à defesa de ideias e de interesses através da linguagem. O registro, a ordenação e a produção dos discursos eram igualmente importantes.

Na Retórica a Herênio também encontramos relações entre boato e poder e algumas referências aos boatos, à fama, à reputação, aos caluniadores. Nela, o autor demonstra a importância política dos boatos e a forma de enfrentá-los, o que ocorreria, assim como no Manual do candidato às eleições, através da oratória. Entretanto, esta fonte textual diferencia-se do Manual do candidato às eleições, pois nela o autor tem como objetivo apresentar uma série de instruções para que o orador construa seu método discursivo e tenha um bom êxito em seu trabalho no contexto de um julgamento.

Deste modo, o orador deveria estar atento às notícias que circulavam, aos boatos que poderiam ser utilizados no julgamento, assim como à fama e à reputação do réu, que é constituída segundo o 
que falam dele, o que poderia ser bom ou ruim. Os boatos, a fama e a reputação poderiam ser utilizados por um defensor ou por um acusador e o orador deveria lidar com este fato no momento de seu trabalho, usando-os segundo seus interesses de defesa ou de acusação, e deveria utilizar seu poder de oratória para enfatizar ou combater algum boato.

$\mathrm{O}$ autor destaca que tanto o acusador como o defensor poderiam utilizar os boatos. Segundo ele, para o acusador, a vida do réu, sua reputação, seus atos anteriores e as suspeitas sobre ele seriam importantes no momento da acusação, na qual o orador deveria adequar a vida do réu a motivação do crime, desqualificando-o com diferentes vícios. Contudo, se ele tivesse uma reputação positiva, o acusador deveria salientar a importância dos fatos em detrimento da sua fama. Já o defensor deveria mostrar a integridade do réu e de sua vida, mas se não pudesse, que culpasse outras coisas. Porém, se o réu tivesse uma má fama, o defensor deveria ressaltar que os boatos são falsos e combatêlos.

O acusador ou o defensor, portanto, deveriam mobilizar os boatos a seu favor, lidando também com a reputação, para que sua argumentação fosse persuasiva. $O$ autor instrui dessa forma seu destinatário:

Em seguida, examinar-se-à a conduta. Primeiro, o acusador considerará se alguma vez o réu empreendeu ato semelhante. Se nada encontrar, buscará saber se alguma vez recaiu sobre ele suspeita parecida; e deverá empenhar-se em tentar adequar a vida pregressa do réu à motivação que pouco antes apontara [...] Assim, ligará o vício do caráter à motivação do crime. Se não 
conseguir encontrar vício compatível com a motivação, encontre um incompatível [...] Se o réu goza de forte reputação de pureza e integridade, dirá o acusador que os fatos, não a fama, devem ser levados em conta, pois o réu antes ocultara seus defeitos; e haverá de deixar patente que ele não se absteve, no passado, de agir mal. O defensor, se puder, exibirá, antes de mais nada, a vida íntegra do réu [...] Se isso for impossível, dada a enorme torpeza e má fama do réu, que se empenhe, antes de tudo, em dizer que se espalharam boatos falsos sobre um homem inocente e utilize o lugar comum de que não se deve dar crédito a boatos. Se não puder fazer nada disso, lance mão do extremo recurso de dizer que não está falando da conduta do réu perante censores, mas das acusações dos adversários perante juízes (Rhet. Her. p.91).

Os boatos poderiam ser usados pelo defensor ou pelo acusador, os quais seriam mobilizados ou debelados. Como um meio de mobilizar um boato a seu favor, espalhando-o, o autor instrui o seu destinatário a ressaltar que um boato não surge por acaso e que, embora existam boatos falsos, o boato em evidência é verdadeiro. Também salienta que uma reputação é baseada em algo, não havendo motivo para sua invenção.

Os boatos também poderiam ser combatidos e, nesse caso, deveriam ser citados boatos falsos e argumentar que foram inventados por homens com qualidades negativas e enfatizar que como qualquer pessoa poderia produzir, espalhar fofocas falsas e prejudiciais contra alguém, essas notícias não deveriam ter crédito. O orador também deveria relatar um boato falso ou verdadeiro sobre um rival e afirmar que ele não acredita no mesmo. Isso é destacado do seguinte modo na fonte documental: 
Falaremos a favor dos boatos se apontarmos que uma reputação não costuma nascer por acaso, sem que algo a fundamente, e se dissermos que não houve motivo para que alguém a fingisse ou inventasse; por fim, demonstraremos que, se outros boatos são falsos, esse é verdadeiro. Falaremos contra os boatos, em primeiro lugar, se explicarmos que muitos são falsos fornecendo exemplos e que os boatos foram forjados por nossos inimigos ou por homens invejosos e maledicentes por natureza; e apresentaremos ou alguma história inventada contra o adversário, e diremos que está na boca do povo, ou um boato verdadeiro que lhe traga prejuízo, dizendo, entretanto, que não nos fiamos nele, porque qualquer homem pode proferir qualquer rumor torpe sobre o que quiser e espalhar um falso boato. No entanto, se um rumor parecer altamente provável, poderemos, com a argumentação, subtrair a fé desse boato (Rhet. Her. p.99-100).

Contudo, assim como relatado no Manual do candidato às eleições, se um rumor parecesse muito provável, através da argumentação o orador poderia subtrair sua fé. O trabalho do orador objetivaria persuadir e vencer, apresentar os argumentos e destruir os do adversário, o que também seria importante para mobilizar ou debelar um boato, enfatizar uma boa fama e reputação ou contornar uma que fosse má no contexto de um julgamento, de defesa ou acusação de um indivíduo.

O autor, portanto, evidencia a importância dos boatos, e como confrontá-los, da fama, da reputação e da relação entre esses conceitos no contexto do julgamento, o que pode ser exemplificado pelo seguinte trecho: "mesmo a dor, se é receada, e a morte, se é temida, são mais leves que a desonra e a infâmia" (Rhet. Her. p.161). 


\section{Considerações Finais}

Podemos compreender que os boatos não eram elementos neutros e indignos (BURKE, 2004), mas que mantinham relações estreitas com o âmbito do poder, influenciando as eleições e os julgamentos na sociedade romana tardo republicana, pois traziam consequências à fama e à reputação dos indivíduos envolvidos nesses processos e modelavam as opiniões públicas dentro de um espaço público de relações sóciopolíticas.

Através dos conselhos e das situações referidas no Manual do candidato às eleições, o autor do mesmo destaca a importância dos boatos dentro de um contexto de intensa disputa política, marcado por tramas e tensões sociais, políticas, econômicas, e a relevância dessas notícias informais para a construção de uma boa fama e reputação do candidato à eleição e de uma imagem positiva da campanha eleitoral do mesmo, ou o contrário, pois alguns boatos poderiam influenciar negativamente o candidato, sua fama, reputação e, consequentemente, sua campanha. $\mathrm{O}$ candidato também deveria atentar-se às notícias que circulavam e poderia utilizar os boatos contra os seus adversários.

A boa reputação e fama de um candidato, sua imagem positiva e de sua campanha, para que fosse prestigioso e admirável pelo povo, estaria estreitamente relacionado com o "falar bem", com as notícias circuladas e também com os boatos, que poderiam mudar as perspectivas do eleitorado, pois eles circulam de pessoa para pessoa, propagando ideias, informações.

Além disso, os boatos seriam de extrema importância no contexto 
de um julgamento. Como elemento dinâmico e que difunde-se, não deveria ser ignorado pelo indivíduo afetado, embora fosse difícil de impedi-lo dentro de uma esfera pública de vivência, independentemente se fossem verdadeiros ou falsos. A sua natureza e os seus usos, portanto, seriam diversos. Eles poderiam ser verdadeiros, pois relacionam-se a um fato, ou falsos, pois alguém poderia disseminar a informação que quisesse, o que poderia ser utilizado no momento do julgamento. Em relação à reputação, esta não seria construída sem razão, pois ela se basearia no que se fala, o que poderia ser a favor ou contra os indivíduos.

Nos dois documentos históricos analisados, portanto, há particularidades e similitudes em relação à atenção atribuída aos usos dos boatos na República romana tardia, ao ato de promovê-los ou combatê-los para os objetivos almejados. Isso deve-se também porque a natureza e os objetivos das fontes históricas são diferentes, já que no Manual do candidato às eleições são evidenciados conselhos sobre uma campanha eleitoral para que o candidato a ela construa uma reputação positiva, usando informações circuladas e os boatos a seu favor, debelando os que poderiam prejudicá-lo e enfatizando a má reputação dos adversários. Já na Retórica a Herênio o autor concede instruções para outrem sobre a defesa e a acusação em um julgamento e, neste contexto, ele poderia utilizar os boatos, a fama e reputação positiva ou negativa do réu a seu favor, mobilizando-os ou combatendo-os.

Em ambos os documentos, por conseguinte, o poder da oratória é destacado e deveria ser utilizado para que os boatos, a fama e a 
reputação fossem mobilizados ou debelados segundo o objetivo do político em sua campanha eleitoral ou do orador em seu trabalho de convencimento na defesa ou acusação de alguém.

\section{Referências bibliográficas}

\section{Fontes antigas}

CÍCERO. Manual do candidato às eleições, Carta do bom administrador público, Pensamentos políticos selecionados. Tradução, introdução e notas de Ricardo da Cunha Lima. Edição bilíngue. São Paulo: Nova Alexandria, 2000.

CÍCERO. Retórica a Herênio. Tradução e introdução Ana Paula Celestino Faria e Adriana Seabra. São Paulo: Hedra, 2005.

\section{Estudos modernos}

BURKE, Peter. Boato Forte. Folha de S. Paulo. São Paulo, 28 de novembro de 2004.

DUPLÁ, A. Interpretaciones de la crisis tardorrepublicana: del conflicto social a la articulación del consenso. Studia Historica. Historia Antigua. Salamanca, v. 25, p. 185-201, 2007.

. Novus sum, consulatum peto, Roma est: el commentariolum petitionis de Quinto Cicerón. Disponível em:

<http://gredos.usal.es/jspui/bitstream/10366/73100/1/Novus_sum\%2c_c onsulatum_peto\%2c_Roma_est_el_.pdf >. Acesso em: 04/05/2014.

FUNARI, P. P. A. Grécia e Roma. São Paulo: Contexto, 2004.

- Propaganda, oralidade e escrita em Pompeia. História. São Paulo, v. 17-18, p. 115-126, 1998-1999.

GUARINELLO, N. L. Imperialismo greco-romano. São Paulo: Ática, 1987. 
Cadernos de Clio, Curitiba, n. ${ }^{\circ}$ 5, 2014

PINA POLO, F. Frigidus rumor: the creation of a (negative) public image in Rome. In:

TURNER, A. et al. (orgs.). Private and Public Lies: The Discourse of Despotism and Deceit in the Greco-Roman World. Londres: Brill, 2010, p. 75-90.

ROCHA DA SILVA, A. C. P. G. Breviário de uma Campanha Eleitoral: O Commentariolum Petitionis de Quinto Cícero. Dissertação (Mestrado em Estudos Clássicos) - Faculdade de Letras, Universidade de Lisboa, Lisboa, 2010.

ROSILLO LÓPEZ, C. "Temo a los troyanos": rumores y habladurías en la Roma tardorrepublicana. Polis: Revista de ideas y formas políticas de la Antigüedad Clásica. Madri, v. 19, p. 113-134, 2007. 